University of Wollongong

Research Online

Faculty of Engineering and Information

Faculty of Engineering and Information

Sciences - Papers: Part A

Sciences

2013

Facile synthesis of hierarchical networks composed of highly interconnected V205 nanosheets assembled on carbon nanotubes and their superior lithium storage properties

\author{
Ruixiang Yu \\ University of Wollongong, ry997@uowmail.edu.au \\ Chaofeng Zhang \\ University of Wollongong, czhang@uow.edu.au \\ Qing Meng \\ University of Wollongong, qm982@uowmail.edu.au \\ Zhixin Chen \\ University of Wollongong, zchen@uow.edu.au \\ Hua-Kun Liu \\ University of Wollongong, hua@uow.edu.au
}

See next page for additional authors

Follow this and additional works at: https://ro.uow.edu.au/eispapers

Part of the Engineering Commons, and the Science and Technology Studies Commons

Research Online is the open access institutional repository for the University of Wollongong. For further information contact the UOW Library: research-pubs@uow.edu.au 


\title{
Facile synthesis of hierarchical networks composed of highly interconnected V205 nanosheets assembled on carbon nanotubes and their superior lithium storage properties
}

\author{
Abstract \\ Hierarchical networks with highly interconnected V205 nanosheets (NSs) anchored on skeletons of \\ carbon nanotubes (CNTs) are prepared by a facile hydrothermal treatment and a following calcination for \\ the first time. Benefiting from these unique structural features, the as-prepared CNT@V205 material \\ shows dramatically excellent electrochemical performance with remarkable long cyclability (137-116 mA \\ h g-1 after 400 cycles) at various high rates (20 C to $30 \mathrm{C}$ ) and very good rate capability for highly \\ reversible lithium storage. The excellent electrochemical performance suggests its promising use as a \\ cathode material for future lithium-ion batteries.

\section{Keywords} \\ storage, lithium, superior, their, nanotubes, carbon, assembled, nanosheets, v2o5, properties, \\ interconnected, facile, highly, composed, networks, hierarchical, synthesis \\ Disciplines \\ Engineering | Science and Technology Studies

\section{Publication Details} \\ Yu, R., Zhang, C., Meng, Q., Chen, Z., Liu, H. \& Guo, Z. (2013). Facile synthesis of hierarchical networks \\ composed of highly interconnected V2O5 nanosheets assembled on carbon nanotubes and their superior \\ lithium storage properties. ACS Applied Materials and Interfaces, 5 (23), 12394-12399.
}

\section{Authors}

Ruixiang Yu, Chaofeng Zhang, Qing Meng, Zhixin Chen, Hua-Kun Liu, and Zaiping Guo 


\title{
Facile Synthesis of Hierarchical Networks Composed of Highly Interconnected $\mathrm{V}_{2} \mathrm{O}_{5}$ Nanosheets Assembled on Carbon Nanotubes and Their Superior Lithium Storage Properties
}

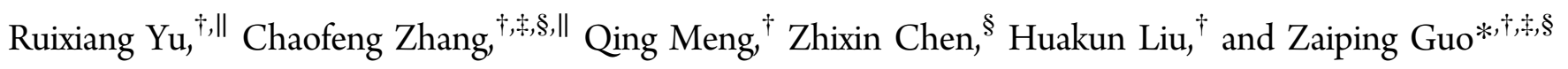 \\ ${ }^{\dagger}$ Institute for Superconducting \& Electronic Materials, University of Wollongong, Wollongong, New South Wales 2522, Australia \\ ${ }^{\ddagger}$ College of Chemistry and Chemical Engineering, Hubei University, Wuhan, Hubei 430062, China \\ ${ }^{\S}$ School of Mechanical, Materials \& Mechatronics Engineering, University of Wollongong, Wollongong, New South Wales 2500, \\ Australia
}

Supporting Information

ABSTRACT: Hierarchical networks with highly interconnected $\mathrm{V}_{2} \mathrm{O}_{5}$ nanosheets (NSs) anchored on skeletons of carbon nanotubes (CNTs) are prepared by a facile hydrothermal treatment and a following calcination for the first time. Benefiting from these unique structural features, the asprepared CNT@ $\mathrm{V}_{2} \mathrm{O}_{5}$ material shows dramatically excellent electrochemical performance with remarkable long cyclability (137-116 $\mathrm{mA} \mathrm{h} \mathrm{g}^{-1}$ after 400 cycles) at various high rates (20 $\mathrm{C}$ to $30 \mathrm{C}$ ) and very good rate capability for highly reversible lithium storage. The excellent electrochemical performance suggests its promising use as a cathode material for future lithium-ion batteries.
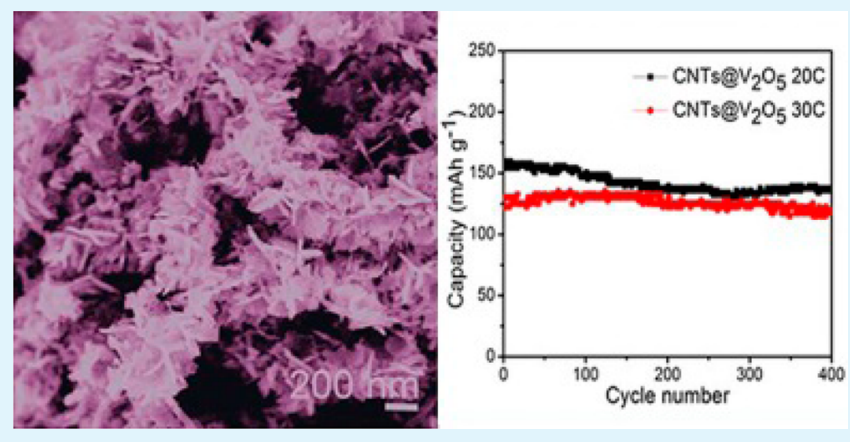

KEYWORDS: carbon nanotubes, $V_{2} \mathrm{O}_{5}$, cathode, lithium ion batteries

\section{INTRODUCTION}

Currently, among all the different kinds of rechargeable batteries, lithium-ion batteries (LIBs), which have been attracting enormous interest, would be one of the best choices for powering electric vehicles (EVs) and hybrid electric vehicles (HEVs). ${ }^{1}$ Their commercial use in EVs and HEVs, however, is still hindered by their low capacity, safety issues, poor stability, and low rate performance. ${ }^{2}$ For further development of LIBs to rise to these serious challenges, substantial efforts have been made to exploit competitive anode and cathode materials. Due to their relatively low capacity compared to anode materials, developing cathode materials with high capacity, high rate capability, and long lifespan is more crucial than it is for anode materials to meet the growing requirements for reducing pollution and greenhouse gas emissions caused by petroleum consumption. ${ }^{3}$

Among the potential cathode materials, orthorhombic vanadium pentoxide $\left(\mathrm{V}_{2} \mathrm{O}_{5}\right)$ has attracted great attention since 1976 as a very promising cathode material for nextgeneration LIBs, due to its low cost and abundant resources, as well as its variety of coordination numbers and oxidation states. $^{4-7}$ Specifically, high theoretical capacities of 294 and 442 $\mathrm{mA} \mathrm{h} \mathrm{g}^{-1}$ can be gained with the intercalation of two or three $\mathrm{Li}^{+}$ions, respectively. ${ }^{6,8}$ Further commercial use of $\mathrm{V}_{2} \mathrm{O}_{5}$ as cathode for LIBs has been impeded, however, by its structural instability and poor kinetics, including its low electric conductivity and slow $\mathrm{Li}^{+}$ion diffusion, resulting in fast capacity fading and low rate capacity. ${ }^{6,9}$ To overcome the kinetic problem and stabilize the structure, one strategy is to design nanostructured forms of $\mathrm{V}_{2} \mathrm{O}_{5}$, for example, hollow/ porous structures, ${ }^{10}$ one-dimensional (1D) nanobelts/nanorods/nanowires, ${ }^{8,11-14}$ and two-dimensional (2D) nanosheets, ${ }^{15}$ for the purposes of shortening transport lengths for both electrons and $\mathrm{Li}^{+}$ions, enlarging the electrode/electrolyte contact area, and reducing the lattice strain associated with lithium intercalation. Although the electrochemical performance of $\mathrm{V}_{2} \mathrm{O}_{5}$ has shown great improvement, most of these nanostructures so far have not proved to be very successful in improving the rate capacity and cyclability of $\mathrm{V}_{2} \mathrm{O}_{5}$ electrodes. Another approach involves combining the active materials with a conductive matrix, thus overcoming the weakness of the poor conductivity. ${ }^{4,8}$ For instance, both $\mathrm{V}_{2} \mathrm{O}_{5}$ nanowires mixed with carbon nanotubes (CNTs) and $\mathrm{V}_{2} \mathrm{O}_{5}$ loaded among sheets of graphene paper have been reported to demonstrate that the use of conductive materials can enhance the capacity retention of the $\mathrm{V}_{2} \mathrm{O}_{5}$ and lead to better rate performance due to the improvement in the electronic conductivity. ${ }^{4,8,16}$ It can be anticipated that conductive materials could play several positive roles in improving the electrochemical performance of $\mathrm{V}_{2} \mathrm{O}_{5}$.

Received: August 11, 2013

Accepted: November 15, 2013

Published: November 15, 2013 
As a new member of the carbon family, carbon nanotubes, first reported by Iijima in 1991, have generated enormous interest in functional nanomaterials and their various applications. ${ }^{17,18}$ Due to the covalent $s p^{2}$ bonds between individual carbon atoms, a carbon nanotube shows a tensile strength around a hundred times higher than that of steel and can tolerate huge strains before mechanical failure. CNTs also possess tunable surface properties, well-defined hollow interiors, and a high theoretical electrical conductivity (exceeding $5 \times 10^{-5} \mathrm{~S} \mathrm{~cm}^{-1}$ at room temperature). All their fascinating properties render them very suitable for advanced applications in the areas of electronics, batteries, and capacitors, as well as heterogeneous catalysis. ${ }^{16,18,19}$ In the past two decades, CNTs have been used as an attractive material for either anode or cathode in LIBs, ${ }^{16,20,21}$ and the encouraging results obtained in these studies are based on the great advantages of CNTs, including high surface area and electrical conductivity. Therefore, it is a very promising strategy to prepare nanosized $\mathrm{V}_{2} \mathrm{O}_{5}$ with a particular structure on a carbon matrix to achieve LIBs with good cycling performance combined with high rate capacity and long cycle life. In the special structure, the CNT network can work as a highly conductive matrix, which also provides supporting interfaces for anchoring the $\mathrm{V}_{2} \mathrm{O}_{5}$ nanomaterials.

Here, we first report a facile hydrothermal approach for synthesizing a hierarchical structured $\mathrm{V}_{2} \mathrm{O}_{5}$ cathode material consisting of CNTs covered by interconnected $\mathrm{V}_{2} \mathrm{O}_{5}$ nanosheets (denoted as CNTs@ $\mathrm{V}_{2} \mathrm{O}_{5}$ ). Such CNTs@ $\mathrm{V}_{2} \mathrm{O}_{5}$ integration networks could possibly exhibit synergism of the robust CNTs and the interconnected $\mathrm{V}_{2} \mathrm{O}_{5}$ nanosheets $\left(\mathrm{V}_{2} \mathrm{O}_{5}-\right.$ NSs). Specifically, the CNTs and interconnected $\mathrm{V}_{2} \mathrm{O}_{5}-\mathrm{NSs}$ could effectively maintain the electrode integrity during charge/ discharge processes with the help of the mechanical strength of the CNTs and the high porosity between the $\mathrm{V}_{2} \mathrm{O}_{5}-\mathrm{NSs}$, and facilitate the electronic and ionic transportation. When evaluated as a cathode material for LIBs, the nanocomposite manifests quite remarkable electrochemical performance in terms of cycling stability at high current rate and superior rate capability.

\section{EXPERIMENTAL DETAILS}

2.1. Materials Synthesis. The CNTs supporting $\mathrm{V}_{2} \mathrm{O}_{5}-\mathrm{NSs}$ were prepared by a facile hydrothermal method, as illustrated in Figure 1.

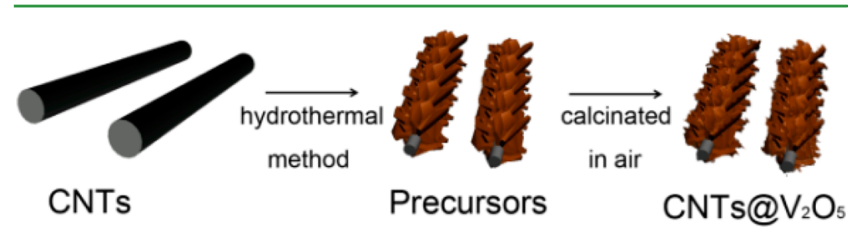

Figure 1. Schematic illustration of the synthesis process for CNTs@ $\mathrm{V}_{2} \mathrm{O}_{5}$.

Typically, acid-treated multiwalled CNTs $(7 \mathrm{mg}$ ) were dispersed in a mixture of cetyltrimethylammonium bromide (CTAB, $0.3 \mathrm{~g}$ ) and isopropyl alcohol (IPA, $30 \mathrm{~mL}$ ) by sonication. Then, 1-methyl-2pyrrolidinone (MP, $50 \mu \mathrm{L}$ ) and vanadium(V) oxytriisopropoxide (VOT, $200 \mu \mathrm{L}$ ) were injected into the black suspension. After 15 minutes of stirring, the mixture was transferred to a Teflon-lined stainless steel autoclave and heated in an oven at $190^{\circ} \mathrm{C}$ for $15 \mathrm{~h}$. The product was collected, washed thoroughly by centrifugation with ethanol several times, and dried overnight in a vacuum oven at $60^{\circ} \mathrm{C}$. The target product, the $\mathrm{CNTs} @ \mathrm{~V}_{2} \mathrm{O}_{5}$ nanosheets, was achieved by heating the precursor in a tube furnace at $320^{\circ} \mathrm{C}$ for $0.5 \mathrm{~h}$ with a heating rate of $0.5^{\circ} \mathrm{C} / \mathrm{min}$. In order to demonstrate the effects of the CNTs, $\mathrm{V}_{2} \mathrm{O}_{5}$ microflowers $\left(\mathrm{V}_{2} \mathrm{O}_{5}\right.$-mf) assembled from $\mathrm{V}_{2} \mathrm{O}_{5}-\mathrm{NSs}$ were also prepared by a similar method without CNTs and surfactant in the preparation process.

2.2. Materials Characterization. The products were characterized by X-ray powder diffraction (XRD; GBC MMA diffractometer, $\mathrm{Cu} \mathrm{K} \alpha, \lambda=1.5406 \AA)$. The morphologies and structures were examined by using a field-emission scanning electron microscope (FESEM; JEOL JSM-7500FA) and a transmission electron microscope (TEM; JEOL, 2011). Thermogravimetric analysis (TGA) was conducted at a heating rate of $10^{\circ} \mathrm{C}$ from room temperature to $800^{\circ} \mathrm{C}$ under air flow.

2.3. Electrochemical Measurements. The working electrode was prepared by mixing the active material $\left(\mathrm{CNTs} @ \mathrm{~V}_{2} \mathrm{O}_{5}\right)$, a conductive agent (carbon black, Super-P-Li), and a binder (polyvinylidene difluoride (PVDF), Sigma-Aldrich) in a weight ratio of 70:20:10 to a homogeneous slurry. After being pasted onto aluminium foil, the prepared working electrodes were dried in a vacuum oven at $120^{\circ} \mathrm{C}$ over $6 \mathrm{~h}$ and were then ready for being assembled into the test cells. The test cells consisted of the active materials as the working electrode, $\mathrm{Li}$ foil as the counter and reference electrode, a microporous polypropylene film as the separator, and $1 \mathrm{M}$ $\mathrm{LiPF}_{6}$ in a 1:1 (v/v) mixture of ethylene carbonate (EC) and diethyl carbonate (DEC) as the electrolyte. The test cells were assembled in an Ar-filled glove box $\left(\mathrm{H}_{2} \mathrm{O}, \mathrm{O}_{2}<0.1 \mathrm{ppm}, \mathrm{Mbraun}, \mathrm{Unilab}\right)$. The galvanostatic measurements were conducted in the voltage range of $2.5-4 \mathrm{~V}$ or $2-4 \mathrm{~V}$ versus $\mathrm{Li} / \mathrm{Li}^{+}$at different constant current densities at room temperature by using a battery cycler (Land CT2001 A). For CNTs@ $@ \mathrm{~V}_{2} \mathrm{O}_{5}$, the specific capacity was calculated based on the mass of $\mathrm{V}_{2} \mathrm{O}_{5}$.

\section{RESULTS AND DISCUSSION}

The crystal phase of the $\mathrm{V}_{2} \mathrm{O}_{5}$ in both the $\mathrm{V}_{2} \mathrm{O}_{5}$-mf and the CNTs@ $\mathrm{V}_{2} \mathrm{O}_{5}$ samples is confirmed by the XRD patterns, as shown in Figure 2a with the peaks labeled, which demonstrates that all the reflections of the samples are in good agreement with the standard pattern of pure orthorhombic $\mathrm{V}_{2} \mathrm{O}_{5}$ phase (JCPDS card no. 89-0612). ${ }^{7}$ The characteristic diffraction peak of CNTs cannot be clearly observed in the XRD pattern of CNTs@ $\mathrm{V}_{2} \mathrm{O}_{5}$, which can be attributed to the following factors: (1) the (110) crystal plane of $\mathrm{V}_{2} \mathrm{O}_{5}$ is very close to the (002) plane of CNTs, as shown in the inset of Figure 2a; (2) the relatively low content of CNTs in the composite (from the TGA result); and (3) the CNTs are fully covered by the $\mathrm{V}_{2} \mathrm{O}_{5}-$ NSs. The CNT content and the thermal properties of CNTs@ $\mathrm{V}_{2} \mathrm{O}_{5}$ were characterized by TGA in air, as shown in Figure S2a (Supporting Information). An abrupt weight loss occurs between 400 and $550{ }^{\circ} \mathrm{C}$, indicating the oxidation and decomposition of CNTs in air. Therefore, the mass fraction of CNTs in the CNTs@ $@ \mathrm{~V}_{2} \mathrm{O}_{5}$ sample is about 17 wt \%.

The morphology and framework of $\mathrm{V}_{2} \mathrm{O}_{5}$-mf and CNTs@ $\mathrm{V}_{2} \mathrm{O}_{5}$ were then characterized by field-emission scanning electron microscopy (FESEM) and transmission electron microscopy (TEM). As shown in Figure $2 b$, the as-prepared precursor has the appearance of a "thorn bush", which is composed of one dimensional "spiny branches" 200-400 nm in diameter, larger than the diameter of the CNTs (shown in Figure S2b, Supporting Information). After calcination in air, flakelike nanosheets of $\mathrm{V}_{2} \mathrm{O}_{5}$ can be observed, as in Figure 2c, which are highly interconnected and cover the CNT skeleton (the inset of Figure 2c). The interconnected $\mathrm{V}_{2} \mathrm{O}_{5}-\mathrm{NSs}$ are in intimate contact with the CNTs, which is favorable for the enhancement of conductivity. In good accordance with the above SEM results, TEM image of $\mathrm{CNT}_{2} @ \mathrm{~V}_{2} \mathrm{O}_{5}$ (Figure 2d) shows that CNTs were surrounded by $\mathrm{V}_{2} \mathrm{O}_{5}$ nanosheets. As can be seen from Figure $2 d$ and $f$, the nanosheets are about 10-20 

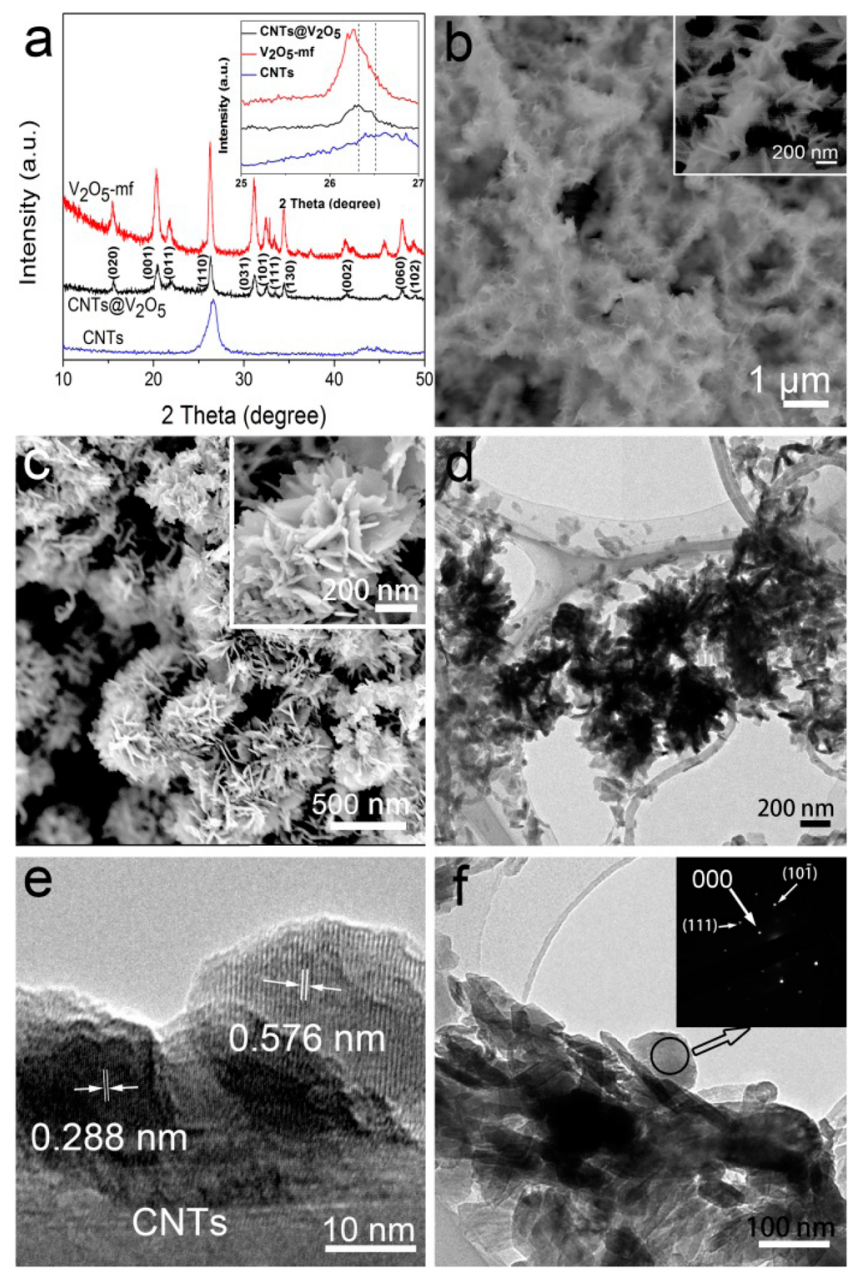

Figure 2. (a) XRD patterns of pure $\mathrm{V}_{2} \mathrm{O}_{5}$, pure CNTs, and CNTs@ $\mathrm{V}_{2} \mathrm{O}_{5}$. SEM images of (b) precursor of $\mathrm{CNTs}_{2} @ \mathrm{~V}_{2} \mathrm{O}_{5}$ and (c) CNTs@ $\mathrm{V}_{2} \mathrm{O}_{5}$, with inset showing higher magnification. (d) TEM images of $\mathrm{CNTs} @ \mathrm{~V}_{2} \mathrm{O}_{5}$. (e) The lattice fringe spacing for the selected area. (f) TEM images of $\mathrm{CNTs} @ \mathrm{~V}_{2} \mathrm{O}_{5}$, the inset shows the corresponding selected area electron diffraction pattern.

$\mathrm{nm}$ in thickness and $50-100 \mathrm{~nm}$ in diameter. The high resolution TEM image of CNTs@ $\mathrm{V}_{2} \mathrm{O}_{5}$ shown in Figure 2e clearly displays the lattice fringes of $\mathrm{V}_{2} \mathrm{O}_{5}$. The interlayer spacings of about 0.576 and $0.288 \mathrm{~nm}$, respectively, correspond to the (200) and (301) planes of $\mathrm{V}_{2} \mathrm{O}_{5}$. The inset of Figure $2 \mathrm{f}$ shows the corresponding selected area electron diffraction (SAED) pattern from one nanosheet, which is recorded from the $[1 \overline{2} 1]$ zone axis which shows the single crystalline nature of the individual $\mathrm{V}_{2} \mathrm{O}_{5}$ naonsheet. The single crystal structure facilitates the transportation of $\mathrm{Li}$ ions. ${ }^{22}$ The as-prepared precursor of $\mathrm{V}_{2} \mathrm{O}_{5}$ - $\mathrm{mf}$ consists of microflowers with diameter of $1 \mu \mathrm{m}$, as shown in Figure S2c (Supporting Information). The inset of Figure S2c (Supporting Information) shows a more highly magnified image of single flower, which is composed of uniform nanosheets. After these flowers were heat treated in air, the as-prepared $\mathrm{V}_{2} \mathrm{O}_{5}$-mf sample almost maintained the same morphology, as can be observed in Figure S2d (Supporting Information).

We have analysed the intermediates collected at reaction time of 5 and $10 \mathrm{~h}$. After $5 \mathrm{~h}$ reaction, only CNTs can be observed from SEM image, indicating the reaction is still at the stage of formation of nanosheets. After reaction for $10 \mathrm{~h}$, there are significant amount of nanosheets formed and surrounded the CNTs, which could be found in the Figure S3 (Supporting Information). Without $\mathrm{CTAB}$ in the process, the nanosheets could not be grown on the CNTs, as shown in Figure S4a (Supporting Information). Therefore, surfactant CTAB helps connect nanosheets of hydrophobic V-based organic compound to the hydrophilic hydroxide radical of CNTs, resulting in Vbased organic compound nanosheets surrounded CNTs. Figure S4b (Supporting Information) shows the SEM image of precursor fabricated without MP. In the figure, the flowerlike interconnected nanosheets cannot be observed, indicating that MP facilitates the self-assembly of nanosheets. Also, we have tried different chemicals to replace MP in the process, for example, diethylenetriamine and dimethylformamide. As shown in Figure S4c and d (Supporting Information), different sized particles appear, fully proving that MP plays a significant role in forming interconnected nanosheets structure around the CNTs skeleton.

To demonstrate the structural advantages of CNTs@ $@ \mathrm{~V}_{2} \mathrm{O}_{5}$, we have evaluated the electrochemical properties of the two samples as cathode for LIBs. Figure 3a presents representative discharge/charge curves of the CNTs@ $\mathrm{V}_{2} \mathrm{O}_{5}$ sample at $1 \mathrm{C}$ in the voltage window of $2.0-4.0 \mathrm{~V}$. In the first cycle, three plateaus appeared at about 3.3, 3.1, and $2.2 \mathrm{~V}$, which can be attributed to the phase transitions $\alpha / \varepsilon, \varepsilon / \delta$, and $\delta / \gamma$, respectively. ${ }^{23}$ On the charge curve, three corresponding plateaus related to the $\mathrm{Li}^{+}$ion deintercalation process are also observed. The discharge-charge voltage profiles are in good agreement with previous reports. ${ }^{9,24}$ The $\mathrm{V}_{2} \mathrm{O}_{5}$-mf sample gives similar plateaus (Figure 3b), but it exhibits larger irreversible capacity loss over 100 cycles compared with the CNTs@ $\mathrm{V}_{2} \mathrm{O}_{5}$. In detail, the capacity of the $\mathrm{V}_{2} \mathrm{O}_{5}$-mf electrode drops from 230 to $118 \mathrm{~mA} \mathrm{~h} \mathrm{~g}^{-1}$ over 100 cycles, while the CNTs@ $\mathrm{V}_{2} \mathrm{O}_{5}$ delivers 285 and $190 \mathrm{~mA} \mathrm{~h} \mathrm{~g}^{-1}$ at the 1st and the 100th cycle, respectively. The cycling performances of the two samples at the current rate of $1 \mathrm{C}$ are shown in Figure 3c. The CNTs@ $\mathrm{V}_{2} \mathrm{O}_{5}$ electrode shows remarkably improved cycling stability, with a capacity loss of $0.34 \%$ per cycle, when compared with the $\mathrm{V}_{2} \mathrm{O}_{5}$-mf sample with a capacity loss of $0.56 \%$ per cycle. For both of these two samples, the coulombic efficiency remains close to $100 \%$ during the cycling (Figure 3c), suggesting the excellent reversibility of the electrodes. To further investigate the cycling performance, the two samples were cycled at the current rates of $20 \mathrm{C}$ and $30 \mathrm{C}$, and the results are shown in Figure $3 \mathrm{~d}$. When the current rate is increased to $20 \mathrm{C}$ and $30 \mathrm{C}$, the capacity of $\mathrm{V}_{2} \mathrm{O}_{5}$-mf electrode drops rapidly to about $40 \mathrm{~mA}$ $\mathrm{h} \mathrm{g}^{-1}$, due to its sluggish kinetics. Amazingly, CNTs@ $\mathrm{V}_{2} \mathrm{O}_{5}$ shows excellent electrochemical performance at $20 \mathrm{C}$ and $30 \mathrm{C}$. Specifically, the capacity slowly drops from 157 to $137 \mathrm{~mA} \mathrm{~h}$ $\mathrm{g}^{-1}$ at the current rate of $20 \mathrm{C}$, and from 127 to $116 \mathrm{~mA} \mathrm{~h} \mathrm{~g}^{-1}$ at the current rate of $30 \mathrm{C}$ after 400 cycles. Charge-discharge voltage profiles of CNTs@ $@ \mathrm{~V}_{2} \mathrm{O}_{5}$ and $\mathrm{V}_{2} \mathrm{O}_{5}$-mf at the rate of 20 $\mathrm{C}$ are shown in Figure S5 (Supporting Information). It can be found that the plateau of $2.2 \mathrm{~V}$ for $\mathrm{CNTs} @ \mathrm{~V}_{2} \mathrm{O}_{5}$ electrode still exists even after 400 cycles (Figure S5a, Supporting Information); however, the plateau of $2.2 \mathrm{~V}$ for the $\mathrm{V}_{2} \mathrm{O}_{5}$-mf electrode disappears (Figure S5b, Supporting Information). Again, this phenomenon demonstrates the advantage of CNTs in the structure. With a narrower voltage window of $2.5-4 \mathrm{~V}$ applied for the two samples, although the capacity is relatively lower, the cycling stability is dramatically improved. Similar phenomena are commonly observed. ${ }^{9}$ As shown in Figure S6 (Supporting Information), the $\mathrm{CNTs} @ \mathrm{~V}_{2} \mathrm{O}_{5}$ sample exhibits excellent electrochemical stability, with high capacities of 105 

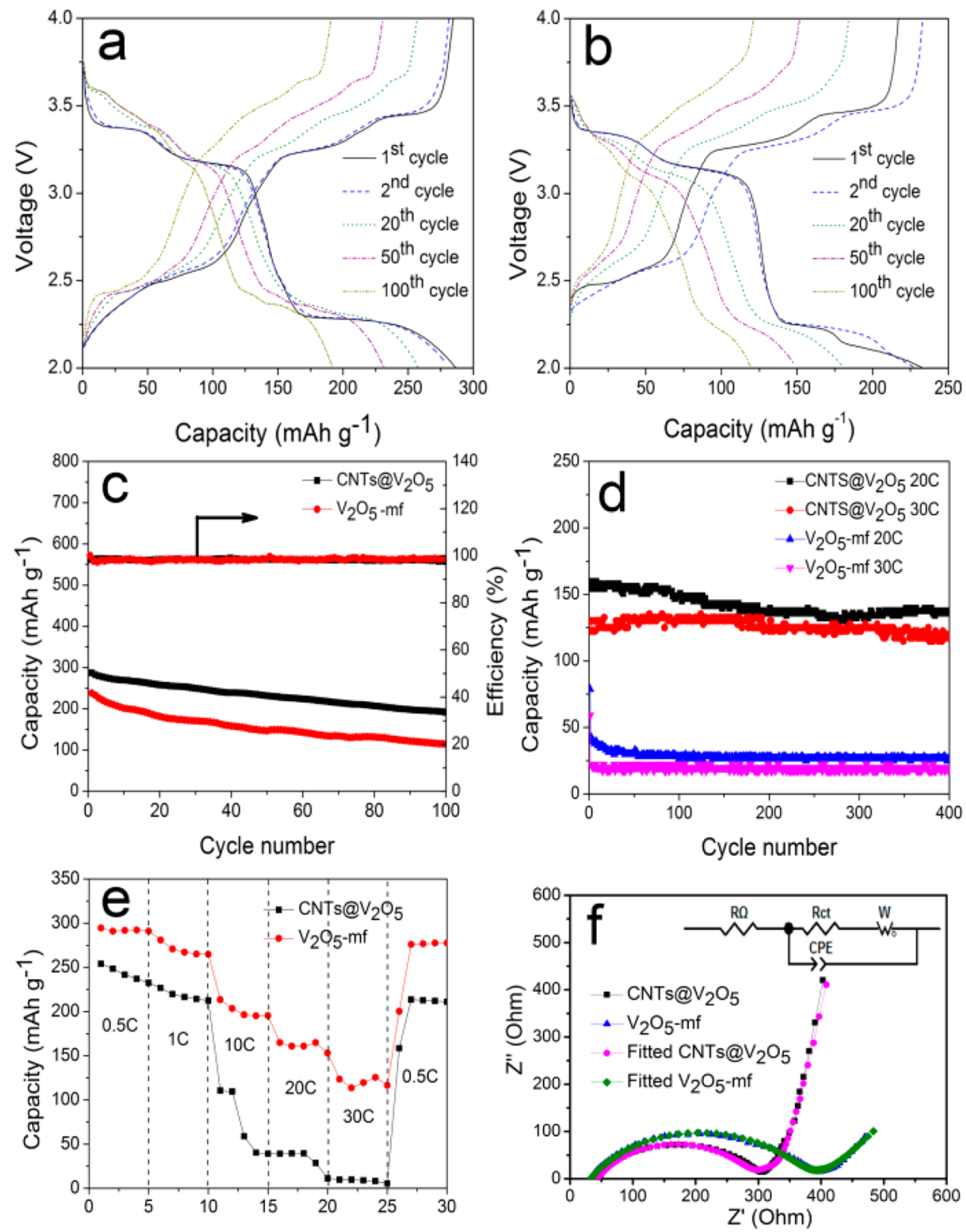

Figure 3. Charge/discharge voltage profiles of CNTs@ $\mathrm{V}_{2} \mathrm{O}_{5}$ (a) and $\mathrm{V}_{2} \mathrm{O}_{5}-\mathrm{mf}(\mathrm{b})$ at the current rate of $1 \mathrm{C}$ for the selected cycles indicated. (c) Cycling performance and coulombic efficiency of CNTs@ $\mathrm{V}_{2} \mathrm{O}_{5}$ and $\mathrm{V}_{2} \mathrm{O}_{5}$ - $\mathrm{mf}$ in the voltage range of 2.0-4.0 V at the current rate of $1 \mathrm{C}$. (d) Cycling performance of CNTs@ $\mathrm{V}_{2} \mathrm{O}_{5}$ and $\mathrm{V}_{2} \mathrm{O}_{5}$ - $\mathrm{mf}$ in the voltage range of 2.0-4.0 V at the current rates of $20 \mathrm{C}$ and $30 \mathrm{C}$. (e) Rate capability of CNTs@ $\mathrm{V}_{2} \mathrm{O}_{5}$ and $\mathrm{V}_{2} \mathrm{O}_{5}$-mf at various current rates. (f) Electrochemical impedance spectra (EIS), fitted EIS curves, and the equivalent circuit (inset) used to fit the impedance data.

and $95 \mathrm{~mA} \mathrm{~h} \mathrm{~g}^{-1}$ that were retained after 500 cycles at the current rates of $20 \mathrm{C}$ and $30 \mathrm{C}$ (corresponding to capacity loss of $0.025 \%$ and $0.031 \%$ per cycle), respectively. In contrast, the $\mathrm{V}_{2} \mathrm{O}_{5}$-mf only delivered specific capacities of about 72 and 30 $\mathrm{mA} \mathrm{h} \mathrm{g}{ }^{-1}$, with fast fading after 500 cycles, at the current rates of $20 \mathrm{C}$ and $30 \mathrm{C}$, respectively. Moreover, the rate capability of $\mathrm{CNTs} @ \mathrm{~V}_{2} \mathrm{O}_{5}$ is also much better than that of $\mathrm{V}_{2} \mathrm{O}_{5}$-ms, as demonstrated in Figure 3e. The CNTs@ $\mathrm{V}_{2} \mathrm{O}_{5}$ electrode displayed better cycling performance than the $\mathrm{V}_{2} \mathrm{O}_{5}$ - $\mathrm{mf}$ at the different current rates. After a deep cycling at $30 \mathrm{C}$, the $\mathrm{CNTs} @ \mathrm{~V}_{2} \mathrm{O}_{5}$ electrode can almost regain its initial capacity when the current rate returns back to $0.5 \mathrm{C}$. For the $\mathrm{V}_{2} \mathrm{O}_{5}$ - $\mathrm{mf}$ electrode, in contrast, the capacity is quickly reduced as the current rate increase, down to about $40 \mathrm{~mA} \mathrm{~h} \mathrm{~g}^{-1}$ at the high current rates of $20 \mathrm{C}$ and $30 \mathrm{C}$. In order to understand the effects of CNTs in the CNTs@ $\mathrm{V}_{2} \mathrm{O}_{5}$ composite electrode, we then investigated the electrochemical performance of working electrodes directly by mixing CNTs@ $\mathrm{V}_{2} \mathrm{O}_{5}$ and PVDF, with less carbon black (5\%) or without carbon black (0\%). As observed from Figure S7 (Supporting Information), the capacity of the CNTs@ $@ \mathrm{~V}_{2} \mathrm{O}_{5}$ electrode drops as the content of carbon black decreases. However, the performance of $\mathrm{CNTs} @ \mathrm{~V}_{2} \mathrm{O}_{5}$ electrode without carbon black is still better than that of $\mathrm{V}_{2} \mathrm{O}_{5}$-mf electrode containing $20 \%$ carbon black. In addition, when the content of carbon black in $\mathrm{V}_{2} \mathrm{O}_{5}$-mf is increased to $30 \%$ (Figure S8) (Supporting Information), the electrochemical performance of $\mathrm{V}_{2} \mathrm{O}_{5}$-mf is still remarkably worse than that of CNTs@ $@ \mathrm{~V}_{2} \mathrm{O}_{5}$. In summary, the CNTs@ 
Table 1. Fitted EIS Results for CNTs@ $\mathrm{V}_{2} \mathrm{O}_{5}$ and $\mathrm{V}_{2} \mathrm{O}_{5}$-mf Electrodes

\begin{tabular}{|c|c|c|c|c|c|c|c|}
\hline & \multicolumn{7}{|c|}{ fitted results } \\
\hline & $R_{\Omega}$ & $R_{\mathrm{ct}}$ & W-R & $\mathrm{W}-\mathrm{T}$ & W-P & CPE-T & CPE-P \\
\hline $\mathrm{CNTs} @ \mathrm{~V}_{2} \mathrm{O}_{5}$ & 43.41 & 247 & 125.8 & 21.32 & 0.43359 & $5.2979 \times 10^{-5}$ & 0.67356 \\
\hline $\mathrm{V}_{2} \mathrm{O}_{5}-\mathrm{mf}$ & 32.84 & 339.4 & 111.9 & 132.5 & 0.29192 & $6.145 \times 10^{-5}$ & 0.65367 \\
\hline
\end{tabular}

$\mathrm{V}_{2} \mathrm{O}_{5}$ electrode exhibits better cycling life and improved rate capability compared to the $\mathrm{V}_{2} \mathrm{O}_{5}$-mf electrode. The main reason is that the $2 \mathrm{D}$ interconnected $\mathrm{V}_{2} \mathrm{O}_{5}-\mathrm{NSs}$ and CNTs could provide large specific surface area for more reactive sites and electrode-electrolyte interface, as well as shortening diffusion pathways, enabling easier $\mathrm{Li}^{+} /$electron transport. In addition, the CNTs in the structure also effectively reduce the polarization when the $\mathrm{CNTs} @ \mathrm{~V}_{2} \mathrm{O}_{5}$ electrodes were cycled at high current rate. As illustrated in Figure S9 (Supporting Information), the conductive CNTs could effectively accelerate the electron transport for the $\mathrm{V}_{2} \mathrm{O}_{5}-\mathrm{NSs}^{25}$ In Figure S9a (Supporting Information), the $\mathrm{V}_{2} \mathrm{O}_{5}$ - $\mathrm{mf}$ electrode was composed of relatively large particles (about $1-1.5 \mu \mathrm{m}$ ) with undesirable interparticle resistance, which failed to provide efficient electron transport between active materials and current collector substrate. On the contrary, besides the carbon black, the CNTs in the CNTs $@ \mathrm{~V}_{2} \mathrm{O}_{5}$ electrode also could provide sufficient ways for charge transfer; loose structures between the $\mathrm{V}_{2} \mathrm{O}_{5}$ sheets are beneficial for fast transfer of $\mathrm{Li}^{+}$(Figure $\mathrm{S} 9 \mathrm{~b}$, Supporting Information). Additionally, the structural robustness of the CNTs is also favorable for the improved electrochemical performance.

To study the effects of the unique structure on the charge transfer, electrochemical impedance spectroscopy (EIS) was performed. Figure $3 \mathrm{f}$ shows the Nyquist plots of the $\mathrm{V}_{2} \mathrm{O}_{5}$-mf and $\mathrm{CNTs} @ \mathrm{~V}_{2} \mathrm{O}_{5}$ electrodes. In the equivalent circuit (inset), $\mathrm{CPE}$ is the constant phase-angle element, involving double layer capacitance; and $W$ is the Warburg impedance, reflecting the solid-state diffusion of $\mathrm{Li}$ ions into the bulk of the active materials. $R_{\Omega}$ and $R_{\mathrm{ct}}$ represent the ohmic resistance (total resistance of the electrolyte, separator, and electrical contacts) and the charge transfer resistance, respectively. The Nyquist plots that are shown for the two samples are similar, displaying a depressed semicircle in the high-middle frequency region, which could be assigned to the charge transfer resistance $\left(R_{\mathrm{ct}}\right)$, and an inclined line in the low frequency region, which represents the Warburg impedance. Table 1 displays the fitted results, which shows that the charge-transfer resistance $R_{\mathrm{ct}}$ for CNTs@ $@ \mathrm{~V}_{2} \mathrm{O}_{5}$ (about $247 \Omega \mathrm{cm}^{-2}$ ) is approximately $70 \%$ of that for $\mathrm{V}_{2} \mathrm{O}_{5}$ - $\mathrm{mf}\left(339.4 \Omega \mathrm{cm}^{-2}\right)$, indicating enhanced charge transfer in the CNTs@ $\mathrm{V}_{2} \mathrm{O}_{5}$ electrode.

\section{CONCLUSIONS}

We have successfully prepared hierarchically structured networks with interconnected $\mathrm{V}_{2} \mathrm{O}_{5}-\mathrm{NSs}$ anchored on skeletons of CNTs by a facile hydrothermal treatment and a following calcination process for the first time. The CNTs and $2 \mathrm{D} \mathrm{V}_{2} \mathrm{O}_{5}-$ NSs could work synergistically to provide sufficient tolerance for the volume variation during $\mathrm{Li}^{+}$insertion/extraction, accelerate the kinetic process of ion diffusion, and exhibits higher electrical conductivity and structural stability. With the benefits of the above unique characteristics, CNTs@ $\mathrm{V}_{2} \mathrm{O}_{5}$ manifests dramatically improved electrochemical performance in terms of long cyclability at high rate and very good rate capability when they are used as cathode material for LIBs. The obtained results suggest that this is a good direction to improve the electrochemical performance of electrode materials for high power LIBs.

\section{ASSOCIATED CONTENT}

\section{Supporting Information}

XRD of the precursor, TGA, addition SEM images of $\mathrm{V}_{2} \mathrm{O}_{5}$-mf, SEM images of precursors synthesized at different conditions, and details of electrochemical results. This material is available free of charge via the Internet at http://pubs.acs.org.

\section{AUTHOR INFORMATION}

\section{Corresponding Author}

*Telephone: 61-2-42215225. E-mail: zguo@uow.edu.au.

\section{Author Contributions}

${ }^{\text {R.Y. and C.Z. contributed equally. The manuscript was written }}$ through contributions of all authors. All authors have given approval to the final version of the manuscript.

\section{Notes}

The authors declare no competing financial interest.

\section{ACKNOWLEDGMENTS}

Financial support provided by the Australian Research Council (ARC) through an ARC Discovery project (DP1094261) is gratefully acknowledged. The authors would also like to thank the Electron Microscopy Centre (EMC) at the University of Wollongong for the electron microscopy characterization.

\section{REFERENCES}

(1) Goodenough, J. B.; Kim, Y. Chem. Mater. 2010, 22, 587-603.

(2) Wang, S. Q.; Li, S. R.; Sun, Y.; Feng, X. Y.; Chen, C. H. Energy Environ. Sci. 2011, 4, 2854-2857.

(3) Hosono, E.; Kudo, T.; Honma, I.; Matsuda, H.; Zhou, H. S. Nano Lett. 2009, 9, 1045-1051.

(4) Seng, K. H.; Liu, J.; Guo, Z. P.; Chen, Z. X.; Jia, D. Z.; Liu, H. K. Electrochem. Commun. 2011, 13, 383-386.

(5) Whittingham, M. S. J. Electrochem. Soc. 1976, 123, 315-320.

(6) Wang, Y.; Cao, G. Z. Chem. Mater. 2006, 18, 2787-2804.

(7) Zhang, C.; Chen, Z.; Guo, Z.; Lou, X. W. Energy Environ. Sci. 2013, 6, 974-978.

(8) Liu, H. M.; Yang, W. S. Energy Environ. Sci. 2011, 4, 4000-4008.

(9) Pan, A. Q.; Wu, H. B.; Zhang, L.; Lou, X. W. Energy Environ. Sci. 2013, 6, 1476-1479.

(10) Rui, X.; Zhu, J.; Sim, D.; Xu, C.; Zeng, Y.; Hng, H. H.; Lim, T. M.; Yan, Q. Nanoscale 2011, 3, 4752-4758.

(11) Mai, L. Q.; Xu, X.; Xu, L.; Han, C. H.; Luo, Y. Z. J. Mater. Res. 2011, 26, 2175-2185.

(12) Wang, Y.; Zhang, H. J.; Lim, W. X.; Lin, J. Y.; Wong, C. C. J. Mater. Chem. 2011, 21, 2362-2368.

(13) Cheah, Y. L.; Aravindan, V.; Madhavi, S. ACS Appl. Mater. Interfaces 2012, 4, 3270-3277.

(14) Perera, S. D.; Patel, B.; Bonso, J.; Grunewald, M.; Ferraris, J. P.; Balkus, K. J. ACS Appl. Mater. Interfaces 2011, 3, 4512-4517.

(15) Liu, Y.; Uchaker, E.; Zhou, N.; Li, J.; Zhang, Q.; Cao, G. J. Mater. Chem. 2012, 22, 24439-24445.

(16) Chen, X. Y.; Zhu, H. L.; Chen, Y. C.; Shang, Y. Y.; Cao, A. Y.; Hu, L. B.; Rubloff, G. W. ACS Nano 2012, 6, 7948-7955.

(17) Iijima, S. Nature 1991, 354, 56-58. 
(18) Zhang, Q.; Huang, J.-Q.; Qian, W.-Z.; Zhang, Y.-Y.; Wei, F. Small 2013, 9, 1237-1265.

(19) Heister, E.; Neves, V.; Lamprecht, C.; Silva, S. R. P.; Coley, H. M.; McFadden, J. Carbon 2012, 50, 622-632.

(20) Wu, H. B.; Lou, X. W.; Hng, H. H. Chem.-Eur. J. 2012, 18, $3132-3135$.

(21) Toprakci, O.; Toprakci, H. A. K.; Ji, L.; Xu, G.; Lin, Z.; Zhang, X. ACS Appl. Mater. Interfaces 2012, 4, 1273-1280.

(22) Zhang, C. F.; Feng, C. Q.; Zhang, P.; Guo, Z. P.; Chen, Z. X.; Li, S.; Liu, H. K. RSC Adv. 2012, 2, 1643-1649.

(23) Delmas, C.; Cognac-Auradou, H.; Cocciantelli, J. M.; Ménétrier, M.; Doumerc, J. P. Solid State Ionics 1994, 69, 257-264.

(24) Li, Y.; Yao, J.; Uchaker, E.; Yang, J.; Huang, Y.; Zhang, M.; Cao, G. Adv. Energy Mater. 2013, 3, 1171-1175.

(25) Wang, Y.; Wang, Y.; Hosono, E.; Wang, K.; Zhou, H. Angew. Chem., Int. Ed. 2008, 47, 7461-7465. 